\title{
ECONOMIA CIRCULAR NO RUMO DA SOCIEDADE CIRCULAR E DA BIOECONOMIA: INICIATIVAS DE COMPOSTAGEM \\ URBANA DE LIXO ORGÂNICO EM SÃO PAULO E FLORIANÓPOLIS
}

\author{
Tobias Gustavo Silva Soares ${ }^{1}$ \\ Barbara Maisonnave Arisi ${ }^{2}$
}

\section{INTRODUÇÃO ${ }^{3}$}

Compostagem é como chamamos a forma natural de reciclagem de matériaprima orgânica que ocorre no meio ambiente, seja esta pela intervenção direta ou indireta dos seres humanos. Atualmente, a compostagem pode ser encontrada em diferentes formas, ocorrendo no próprio meio ambiente ou com manejo domiciliar para a destinação dos resíduos sólidos orgânicos com as "composteiras domésticas". A preocupação mundial em relação aos resíduos sólidos, em especial os domiciliares, tem aumentado ante o crescimento da produção, do gerenciamento inadequado e da falta de áreas de disposição final de resíduos sólidos nos centros urbanos (Jacobi \& Besen, 2011).

Atualmente, a compostagem urbana é uma das estratégias em realizar uma gestão adequada dos resíduos orgânicos, praticada de forma consciente e que seja efetiva em seu resultado final. Um das proposições importantes dessa estratégia para que seja eficiente em termos ambientais é que o manejo se faça no próprio local da geração do "resíduo orgânico", para que a logística de manejo de resíduos sólidos seja simplificada por uma consciência ambiental e promova um bem estar social aos geradores e a toda a comunidade que os cerca. Desse modo, o conceito de moradia se transforma de maneira sutil para uma ideia de comunidades sustentáveis, como proposto pelos Objetivos de Desenvolvimento Sustentável, da Organização das Nações Unidas ${ }^{4}$.

\footnotetext{
${ }^{1}$ Universidade Federal da Integração Latino-Americana, Brasil. Email: tobiasgustavoh@gmail.com ORCID id: https://orcid.org/0000-0001-9866-1576

${ }^{2}$ Universidade Federal de Santa Catarina, Brasil. Email: barbara.arisi@gmail.com ORCID id: https://orcid.org/0000-0001-7560-9636

${ }^{3}$ O presente trabalho foi realizado com apoio da Coordenação de Aperfeiçoamento de Pessoal de Nível Superior - Brasil (CAPES) - Código de Financiamento 001.

4 Proposto pela ONU desde 2015, são metas a serem alcançadas até 2030, que visam gerar ações mundiais num intuito de (...) "erradicação mundial da pobreza e agendas como saúde, saneamento, segurança
} 
Dessa forma, o manejo de resíduos passa a ser considerado do ponto de vista social, ou seja, não mais considerado apenas pela escala do indivíduo, mas pela do coletivo que produz resíduos orgânicos e passa a participar do processo de coresponsabilização do destino apropriado dado aos resíduos orgânicos produzidos por tal coletivo. A gestão e a disposição inadequada dos resíduos sólidos causam impactos socioambientais, tais como: degradação do solo, comprometimento dos corpos d'água e mananciais, intensificação de enchentes, contribuição para a poluição do ar e proliferação de vetores de importância sanitária nos centros urbanos e catação em condições insalubres nas ruas e nas áreas de disposição final (Besen, 2010).

Segundo Besen, a região metropolitana de São Paulo, com seus 19,7 milhões de habitantes, dos quais 11 milhões moram no município de São Paulo, é a maior do Brasil, e um dos maiores aglomerados urbanos do mundo, uma megalópole responsável pela produção estimada de 16.233 toneladas por dia ou quase seis milhões de toneladas por ano de resíduos sólidos domiciliares. Essa quantidade corresponde a cerca de 10\% do lixo coletado no país, e o município de São Paulo é responsável pela geração de mais de 62,5\% desses resíduos (idem). Portanto, na megalópole, a compostagem domiciliar ou comunitária pode ser executada por autogestão ou por gestão terceirizada. A compostagem doméstica de resíduos sólidos pode promover um deslocamento na forma de manejo de resíduos, com baixo custo e emissão de $\mathrm{CO}^{2}$, e incentivar novas maneiras do cidadão participar dos processos sociopolíticos locais e também, consequentemente, gerar renda para comunidades que se empoderam também como atores políticos nesses processos. Famílias de baixa renda podem considerar ações como esta como uma nova fonte de geração econômica, local e processual, e nem sempre apenas o dinheiro será o produto de troca.

Nesse artigo, iremos apresentar duas experiências de compostagem de resíduos orgânicos domésticos que exemplificam duas formas de promover a compostagem doméstica em grandes centros urbanos. Durante um ano, para nossa pesquisa de iniciação científica realizada pela Universidade Federal da Integração Latino-Americana (UNILA), Tobias Gustavo fez um levantamento na internet de iniciativas inovadoras de reciclagem de resíduos orgânicos em duas capitais no Brasil: São Paulo e Florianópolis. Com base em nosso resultados, consideramos que a compostagem urbana é uma das

alimentar, educação, cidades sustentáveis entre outros". Trecho retirado do site oficial do programa no Brasil ( https://brasil.un.org/pt-br/sdgs ) 
soluções sustentáveis e coerentes para as práticas de manejo de materiais e resíduos orgânicos. Nosso objetivo inicial era conhecer as principais iniciativas governamentais e não governamentais para a compostagem nessas duas cidades.

Como metodologia, realizamos revisão bibliográfica de artigos científicos sobre resíduos orgânico e compostagem urbana e sobre os conceitos de "tecnologia social" (Dagnino \& Novaes, 2004; Pozzebon, 2015), "economia circular" (McDonough \& Braungart, 2002), "sociedade circular" (Hettemäki et ali, 2017) e "bioeconomia circular" (Research Group Obsolescence, 2019). A seguir, fizemos um levantamento de dados na internet a partir de pesquisa booleana (utlizando os termos "and", "or", "not") sobre as iniciativas privadas, comunitárias e municipais para o manejo adequado do lixo orgânico com compostagem nessas duas cidades. Por fim, analisamos e debatemos sobre o material coletado e realizamos uma comparação entre essas duas iniciativas: Composta SP, em São Paulo (SP), e Revolução dos Baldinhos, em Florianópolis (SC), ambas no Brasil.

\section{Política Nacional de Resíduos Sólidos e experiências locais}

A pesquisa apresenta as iniciativas de caráter participativo/comunitário de manejo dos resíduos orgânicos. Encontramos diversas formas de gestão heterogêneas em São Paulo e Florianópolis, algumas eram fruto de parcerias do setor público e setor privado e outras eram oriundas da participação da sociedade civil, iniciativas que chamaremos de comunitárias. Dessa forma, filtramos quais das iniciativas públicas e comunitárias executam a Política Nacional de Resíduos Sólidos (PNRS) e o Plano de Gestão Integrada de Resíduos Sólidos (PGIRS), que de acordo com a LEI No 12.305, de 2 de Agosto de 2010, determina novas formas de entender, distinguir e trabalhar os resíduos recicláveis e rejeitos. Ambos os projetos de manejo de resíduos sólidos que iremos apresentar em detalhe foram realizadas a partir de ações de gestão participativa em consonância com o estabelecido pela PNRS, são eles: Composta SP, em São Paulo (SP), e a Revolução dos Baldinhos, em Florianópolis (SC).

\section{COMPOSTA SP - 2014}

O projeto Composta SP começou em 2014, promovido pela empresa Morada Da Floresta que o idealizou e desenvolveu. A Morada da Floresta trabalhou em parceria com a Prefeitura de São Paulo, subcontratada pelas empresas Loga e Ecourbis, as duas 
concessionárias responsáveis no período da execução do projeto pelos serviços de coleta domiciliar no município. O Composta SP procurou incentivar a compostagem doméstica como método de educação ambiental. Tal projeto impulsionou, em nível municipal, a distribuição gratuita de duas mil composteiras com minhocas (também chamados "minhocários") oferecidas em diferentes tamanhos (pequeno, médio e grande) para núcleos familiares de todas as camadas sociais. Por meio de uma pesquisa online, funcionários da Morada da Floresta realizavam uma entrevista com moradores para saber se queriam participar do projeto e depois buscavam identificar qual tamanho de composteira era adequada, levando em conta a produção e o consumo de matéria orgânica por família/residência.

As etapas de produção e a execução foram divididas em 7 fases:

(1) Convite, cadastro, seleção e recrutamento de pessoal. Por meio de questionário online e através da demanda espontânea, nessa fase foram contatados síndicos de prédios de diferentes perfis socioeconômicos, além de cartas convites à diretores de escolas públicas e privadas e lideranças comunitárias. Nesse momento, as duas mil famílias que foram contempladas com a composteira doméstica receberam a confirmação por e-mail, e um termo de compromisso que indicava o comprometimento com as demais fases do projeto.

(2) A segunda fase visava o recrutamento e a orientação aos educadores. Por meio de contratação temporária, foram selecionados potenciais educadores ambientais para as oficinas de capacitação e por livre adesão de participantes.

(3) A terceira fase foi dedicada à capacitação dos participantes sobre compostagem doméstica e plantio urbano. Nesta fase, as composteiras foram entregues em conjunto com oficinas de conscientização ambiental e sobre o manejo da composteira, de forma a incentivar a pequenos plantios urbanos.

(4) A quarta fase era para orientação à prática de agricultura urbana. Foram demonstradas diversas técnicas de manejo: a retirada do húmus da composteira, métodos de secagem e peneiração para manter as minhocas em reprodução e continuar o ciclo, além de revitalização de vasos com uso de garrafas PET (de plástico) e caixas TetraPak e técnicas de plantio em pequenas áreas verdes.

(5) A quinta fase foi de acompanhamento e suporte técnico aos participantes, por meio de telefone, e-mail e a criação de um grupo virtual em rede social para a trocas de experiências e de desafios e dúvidas enfrentados pelos participantes. 
(6) A sexta fase foi dedicada ao monitoramento e encerramento, através de questionários online. Foram realizadas duas pesquisas nesse período do projeto, para a avaliação final.

(7) Finalmente, a sétima e última fase foi a sistematização e análise dos dados, produção de relatórios com resultados quantitativos sobre a execução do projeto.

A seguir, apresentamos imagens dos minhocários distribuídos para a população em São Paulo. Na ocasião, o pesquisador Tobias Gustavo foi selecionado para participar do Composta SP. Como nativo e pesquisador dessa ação pública, Gustavo pode acompanhar e irá, nesse artigo, demonstrar o processo de compostagem na prática, através de imagens do seu acervo pessoal e também de imagens publicadas por outros participantes no grupo de trocas de conhecimento do Facebook. Até o momento em que escrevemos esse artigo, o grupo no Facebook encontra-se ativo. Nele, os participantes publicizam suas experiências em ações de cunho ambiental em seus lares e bairros, e agora compartilham suas experiências com a compostagem e o plantio urbano incrementadas durante o período da pandemia.

Em 2014, os participantes ao receberam a composteira e um kit que continha: serragem, minhocas californianas, três caixas vazias, 1 pacote de húmus, 1 composto "neem" ${ }^{5}$ e 1 manual ilustrado. Lembramos que os tamanhos foram destinados levando em conta o dado sobre o número de habitantes em cada residência. Essa é uma característica importante, por conta da quantidade de lixo orgânico gerado em cada residência.

\footnotetext{
5 O "neem" é conhecido também como biopesticida, para os praticantes de agricultura biodinâmica e agricultura orgânica, pelo seu potencial químico não ser nocivo à aves, abelhas e minhocas.
} 


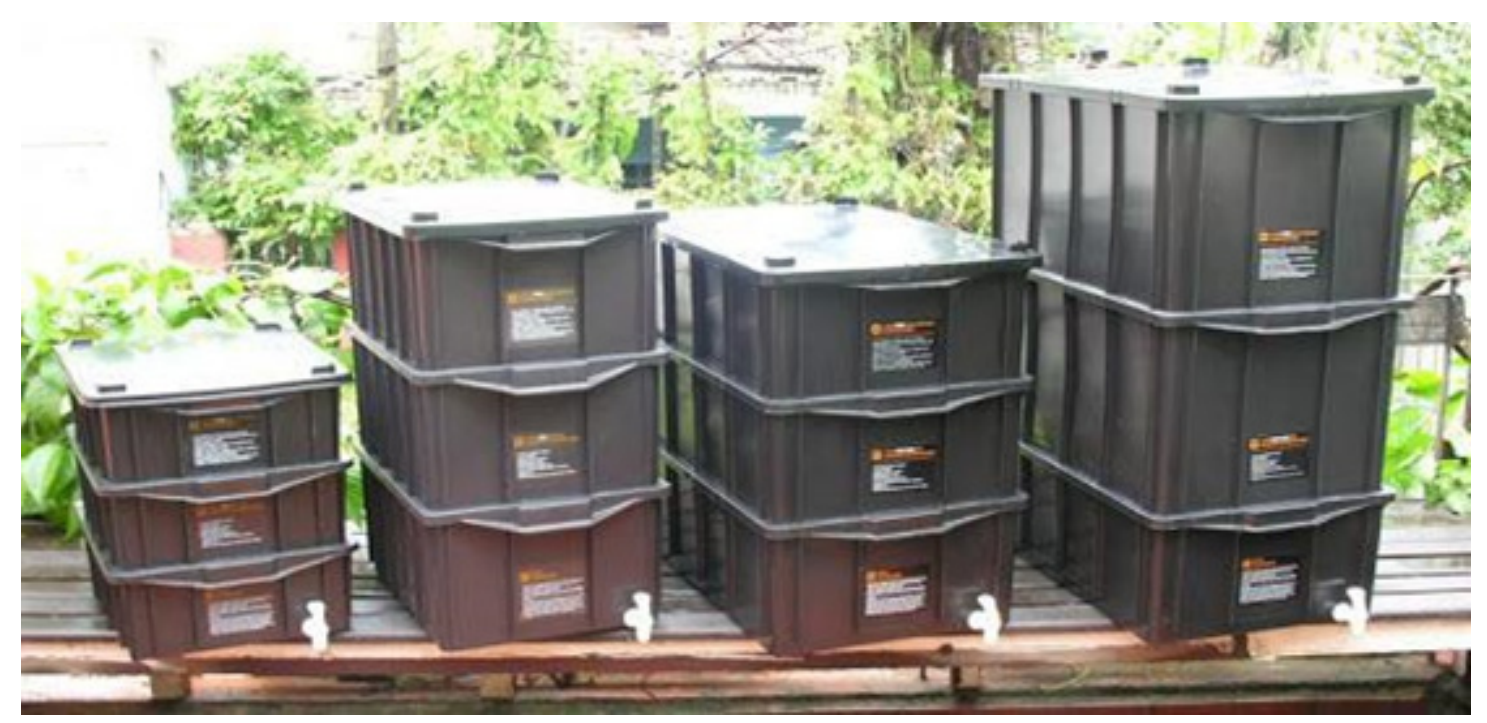

Fig.1: Modelos de composteiras (ou minhocários) distribuídos para os participantes do projeto, imagem disponível em https://www.picuki.com/tag/compostaSP

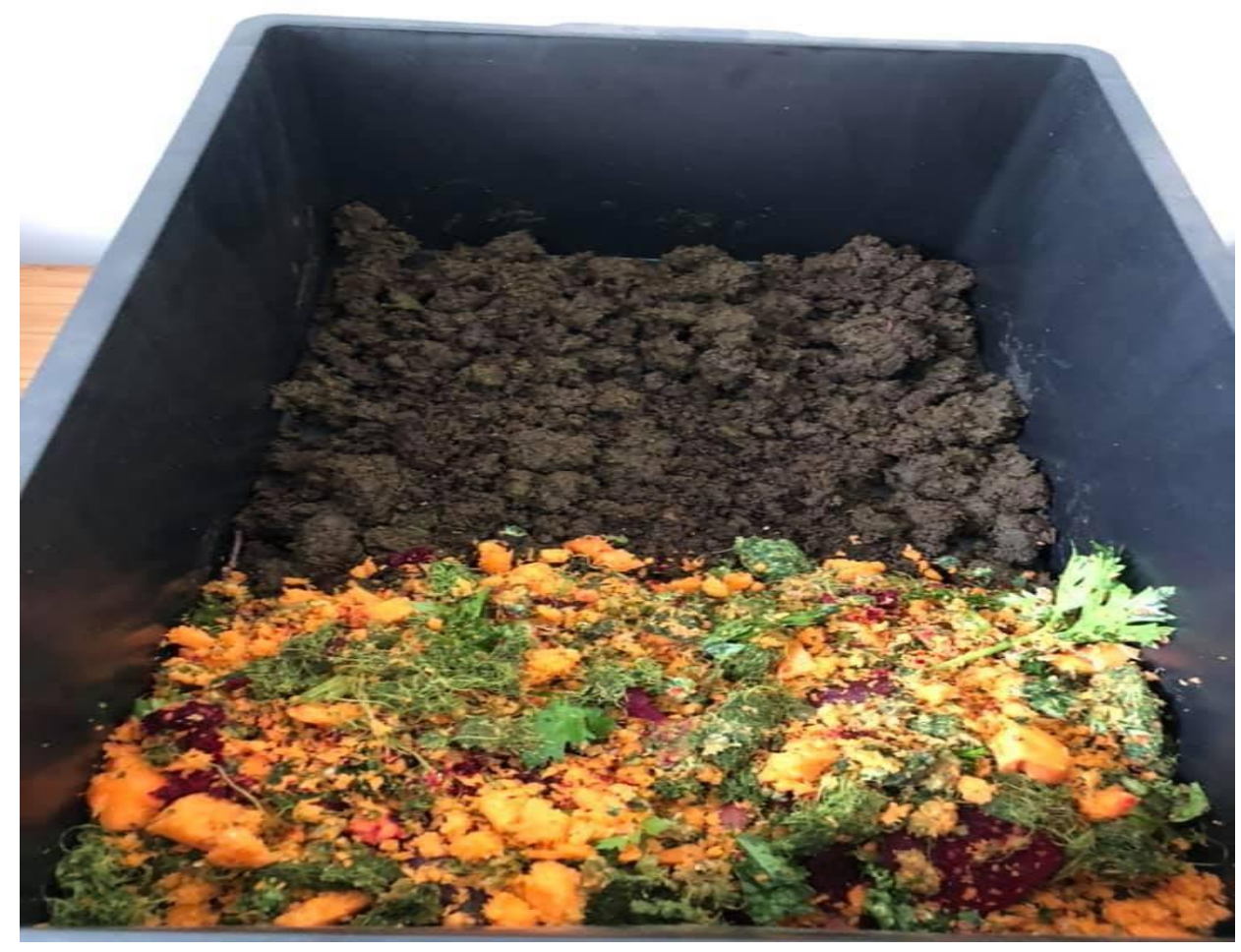

Fig.2: Grupo Composta SP - Facebook

Nessa imagem (figura 2), podemos ilustrar o processo de aeração contido na tecnologia da composteira (figura 1). Como será mostrado adiante, esse material orgânico será revestido por uma camada de matéria seca, que promoverá um ambiente rico em $\mathrm{O}^{2}$ e será adequado para degradação do lixo orgânico e sua transformação em húmus. 


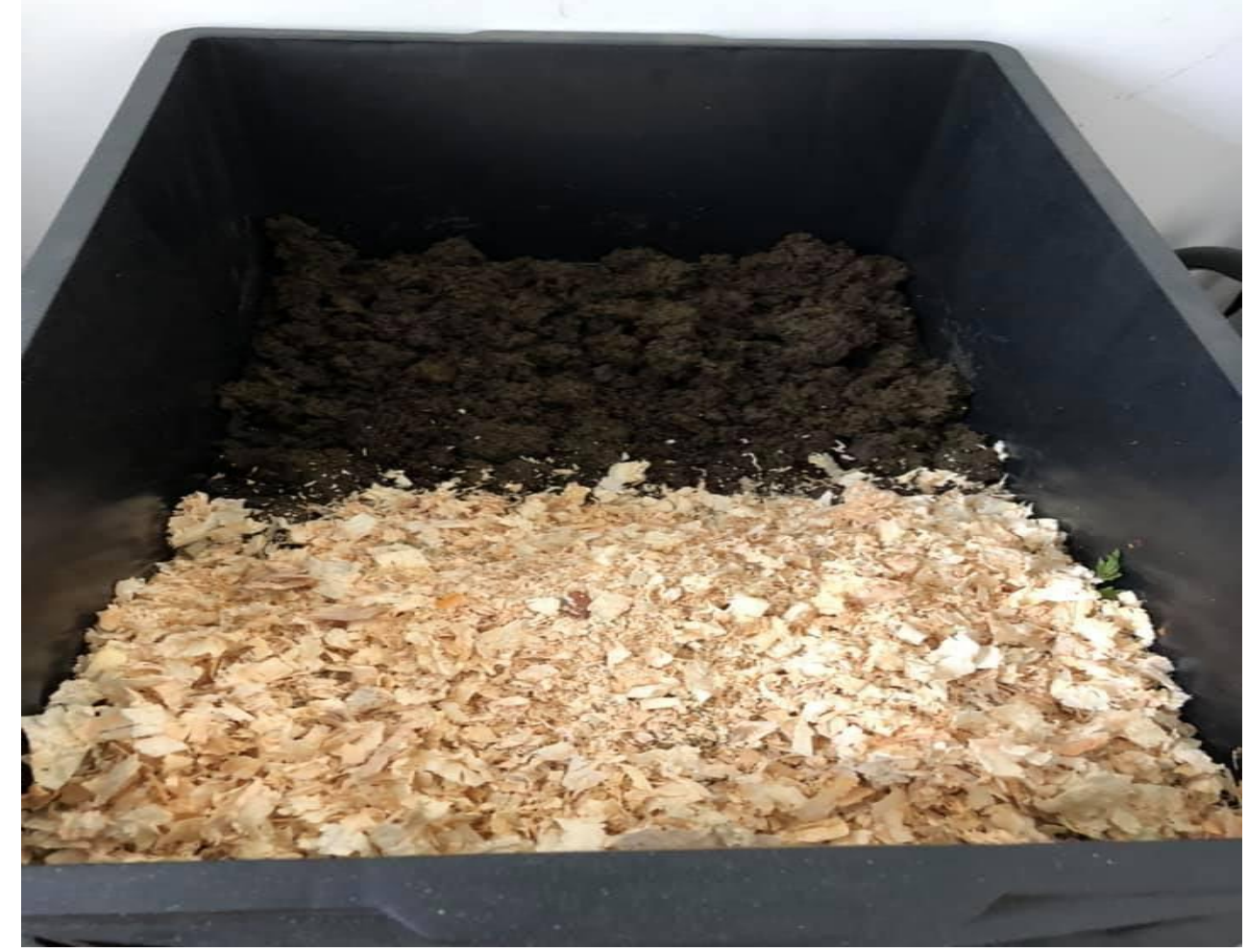

Fig. 3 Serragem para cobrir o material de resíduos orgânico domiciliar.

Grupo Composta SP - Facebook

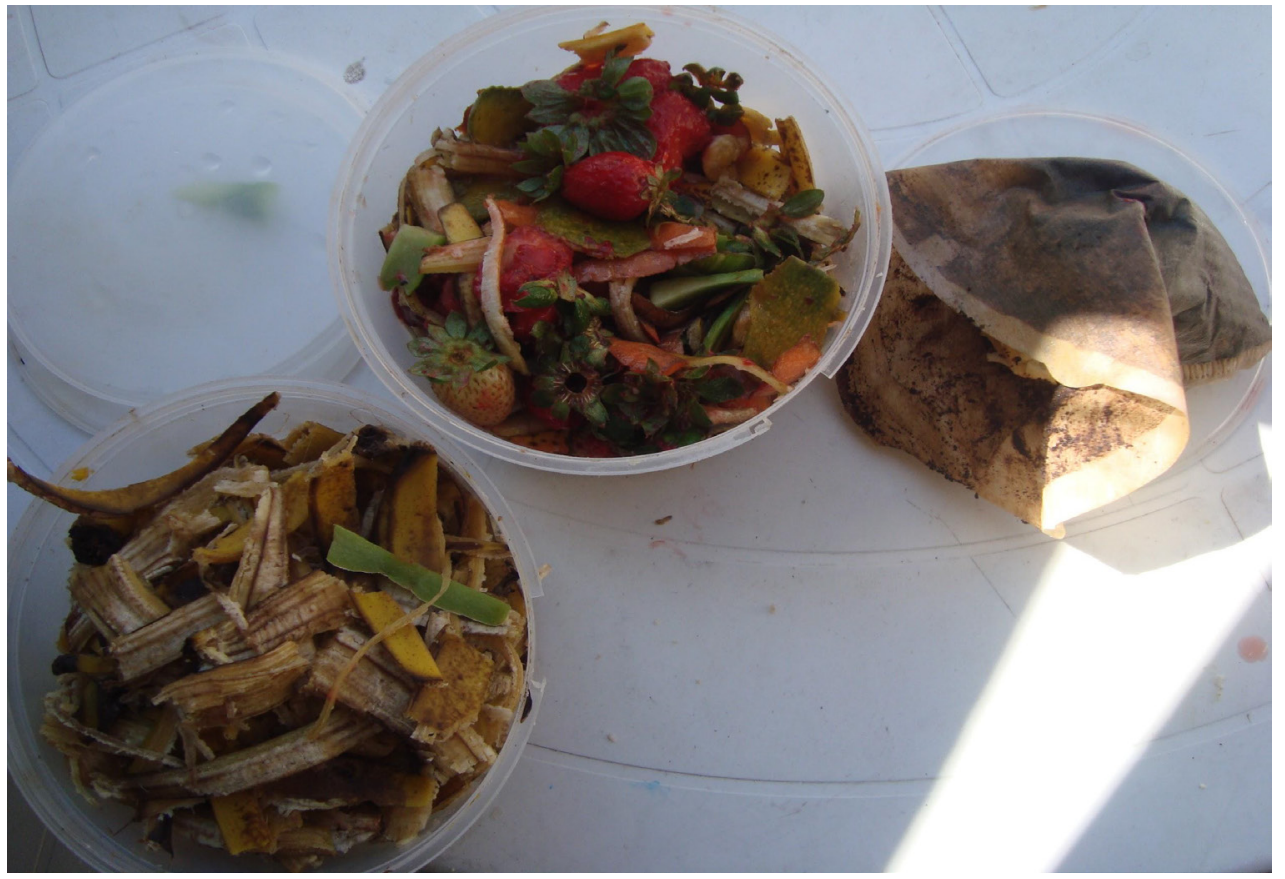

Fig.4 Resíduos orgânicos e de papel que "alimentam” a composteira.

Arquivo Pessoal de Tobias Gustavo.

No processo de montagem da composteira, mostramos a separação dos alimentos orgânicos (figura 4) que serão agrupados em camadas e então serão cobertos pela 
serragem (figura 3) ou outros materiais secos que proporcionarão um ambiente temperado, ou seja, com um clima ameno para os microorganismos próprios do solo, se reproduzirem e criarem assim um ambiente úmido e similar ao próprio solo.

Estes materiais secos, podem variar de acordo com a tecnologia empregada ao se compostar o lixo orgânico, podendo ser utilizadas palhas secas ou serragem de marcenarias e folhas secas na vermicompostagem ${ }^{6}$. Esses materiais secos também podem ser usados na compostagem termofílica, conhecida também como sistema de leiras que, além do material acima mencionado, também utiliza o esterco de gado, indicado pelas especificidades de seus nutrientes.

Paisagens urbanas imbricadas com as paisagens rurais são percebidas em algumas das regiões mais periféricas da cidade de São Paulo, bem como em outras regiões do Brasil. Essa conjunção do ambiente urbano e do ambiente rural oferece para a agricultura urbana muitas perspectivas.

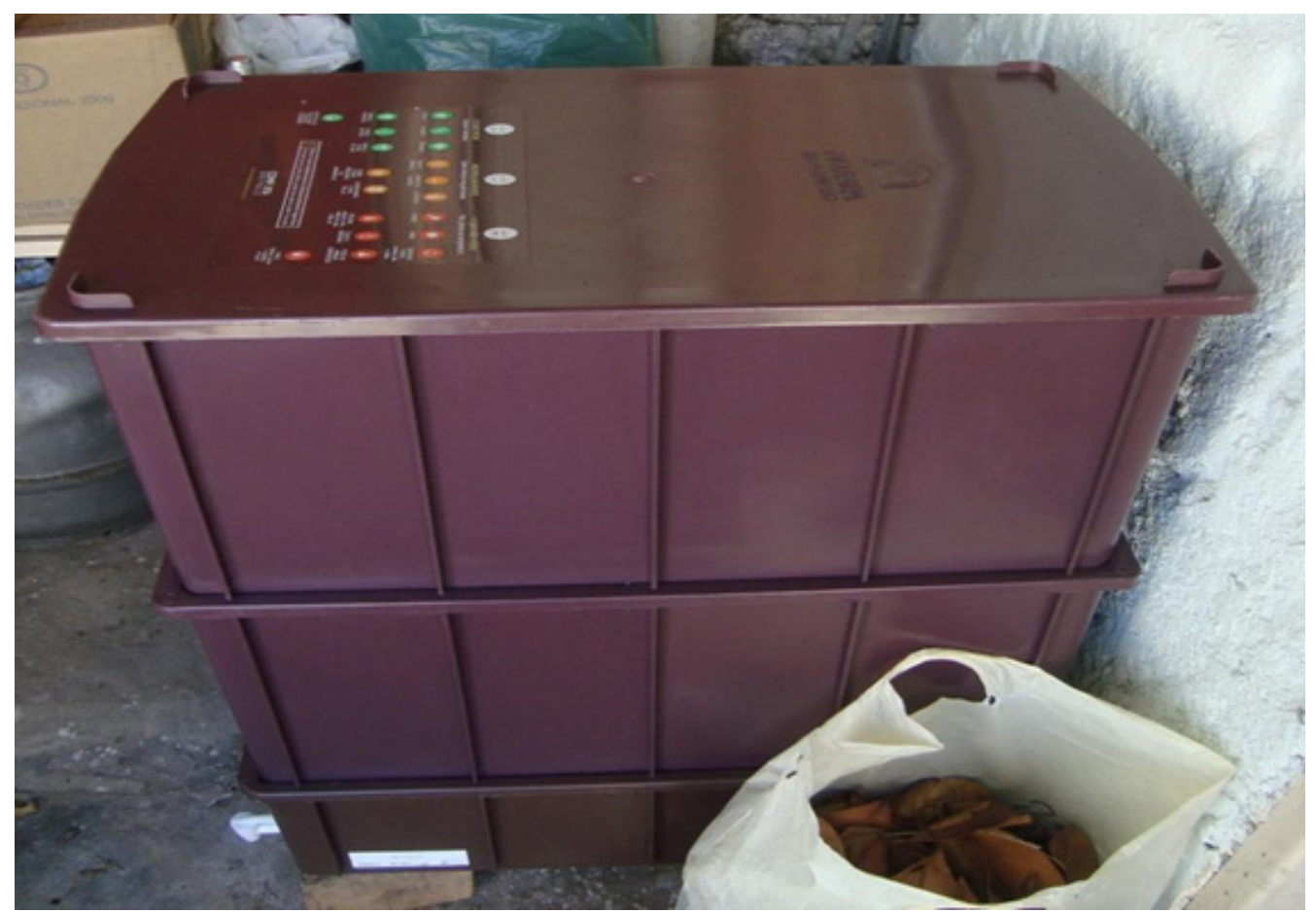

Fig.5 A composteira nos fundos da casa e ao lado uma sacola com folhas que serão usadas para cobrir os resíduos alimentares.

Arquivo Pessoal de Tobias Gustavo.

\footnotetext{
${ }^{6}$ Vermicompostagem é o processo de transformar desperdícios orgânicos em composto de alta qualidade em pouco tempo e sem grandes exigências de espaço, tempo ou equipamento, utilizando minhocas.
} 
Nesse cenário, o uso da composteira no ambiente urbano como uma metrópole, ou megalópole como São Paulo, pode favorecer a educação ambiental pois oferece novas experiências e vivências para crianças, jovens, adultos e idosos. Ao preparar e cuidar de sua composteira residencial, os participantes podem ampliar sua compreensão e o seu olhar para o meio ambiente, é um engajamento vivencial de observar um processo natural de compostagem de resíduos orgânicos e suas implicações reais nos modos da natureza degradar resíduos de alimentos orgânicos que criarão o solo fértil de novos alimentos.

O projeto tinha essa finalidade: propor aos participantes perceber o seu próprio consumo e a destinação final do seus resíduos sólidos.

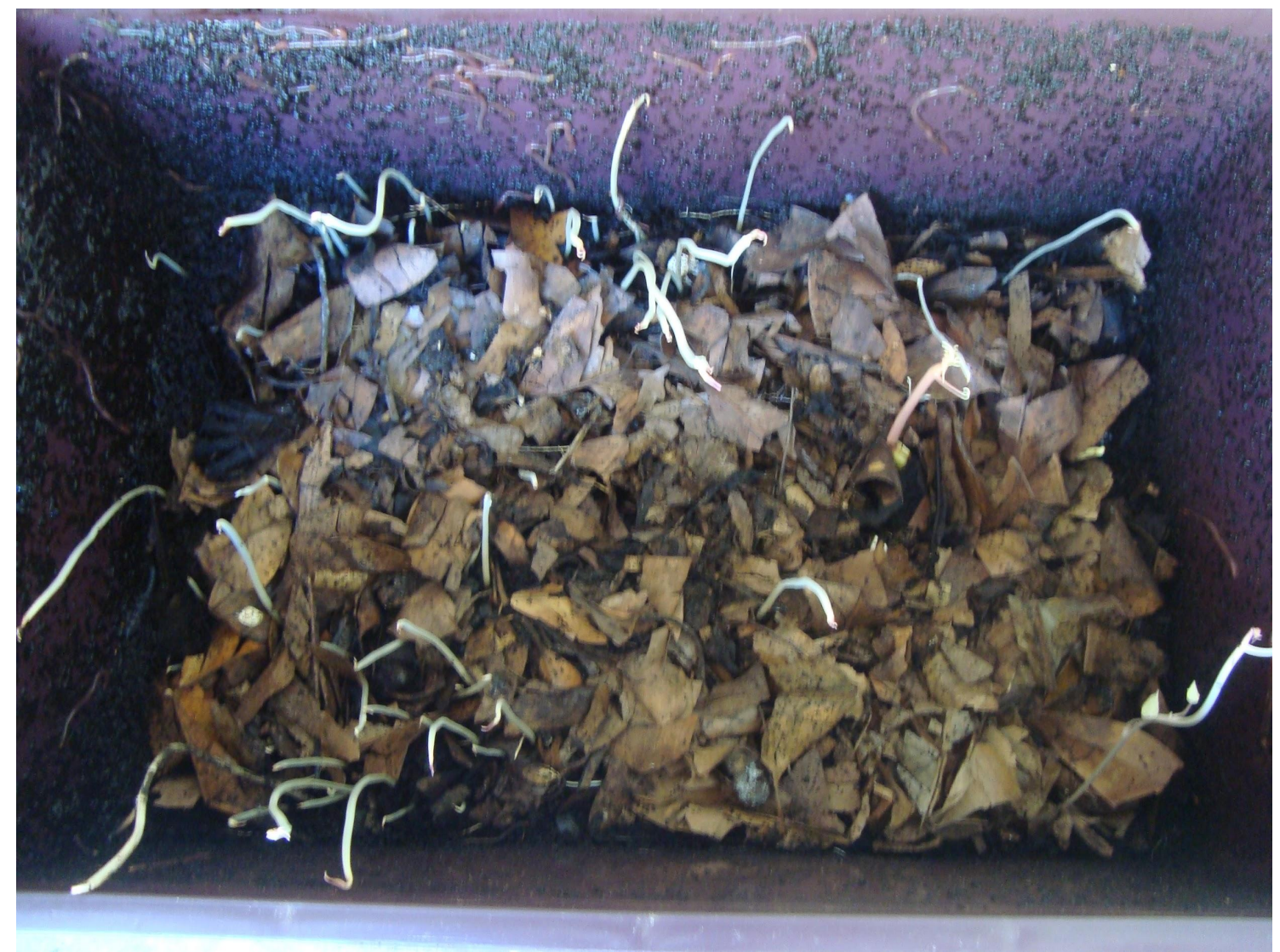

Fig.6 Nessa imagem, vemos brotos de novas plantas crescendo na própria composteira.

Arquivo Pessoal de Tobias Gustavo. 
Muitos fatores foram desafiantes no ato de compostar, como exemplo, citamos as infestações de larvas, ácaros e drosófilas ${ }^{7}$, o que suscitou uma ampla participação através do grupo online na página do Facebook. Alguns encontros presenciais foram realizados nos entornos de bairros de classes média e alta, ou seja, longe dos aterros sanitários que, no Brasil, costumam estar localizados nos bairros onde moram as populações pobres e vulnerabilizadas socioeconomicamente. Tais aterros ou locais de destino de resíduos acarretam implicações de riscos para a saúde das populações que vivem nesses bairros. Assim, os relatos dessas infestações de pragas foram um dos assuntos mais discutidos no meio virtual. Para combater essas infestações, a utilização do "neem" (o biopesticida) foi a mais indicada. Seu uso foi testado pelos participantes e sua eficácia foi aprovada no controle de pragas no processo da vermicompostagem em pequenos espaços domésticos.

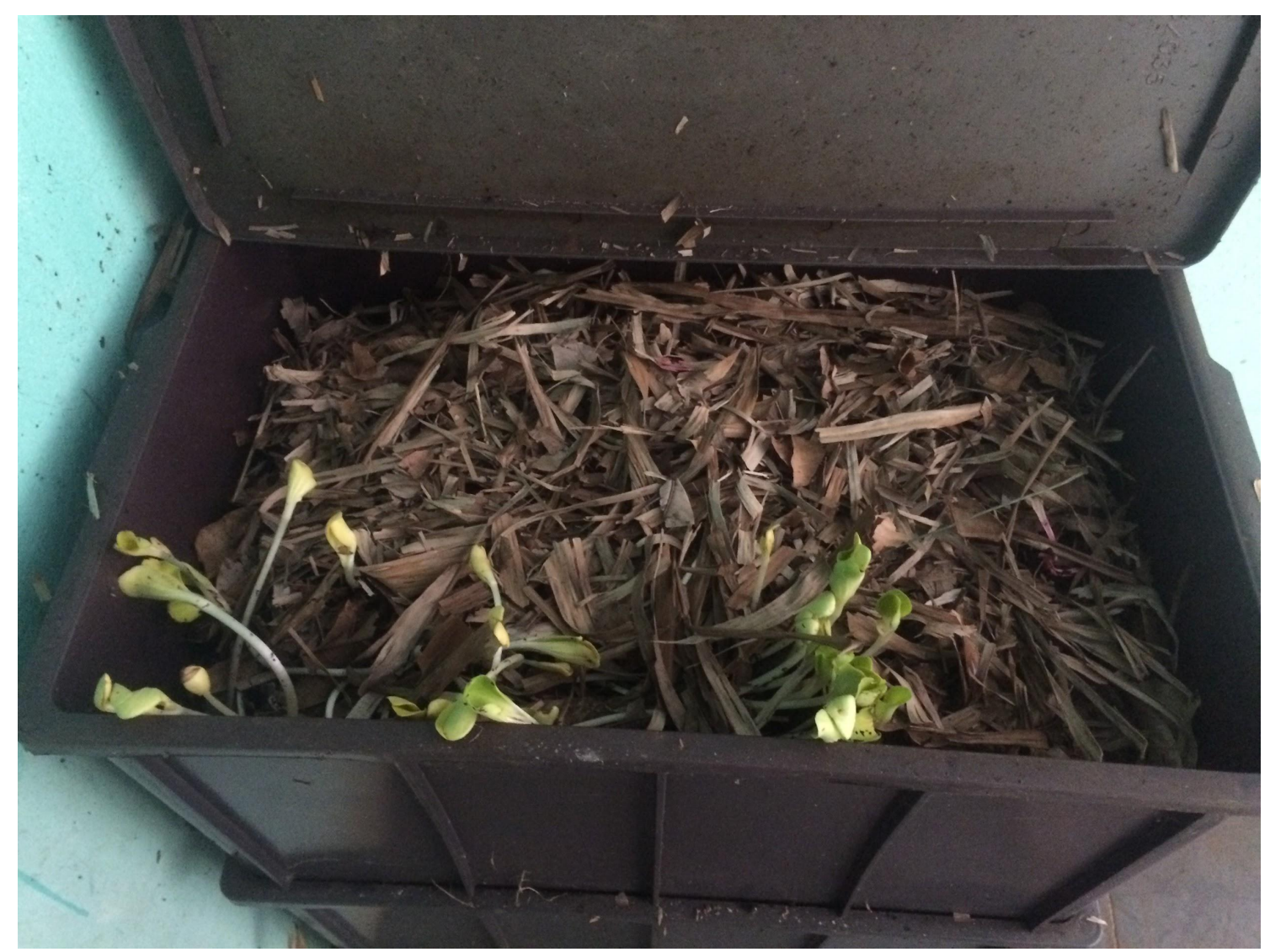

Fig.7 Nessa imagem, vemos plantas que tentam nascer na composteira, cobertas por restos de jardim. Arquivo Pessoal de Tobias Gustavo.

7 Processos biológicos presentes numa vermicompostagem, que ocorrem através de alterações no microclima das caixas de composto ou invasão de moscas (drosófilas) ou outras pragas no ciclo de vida das larvas. 


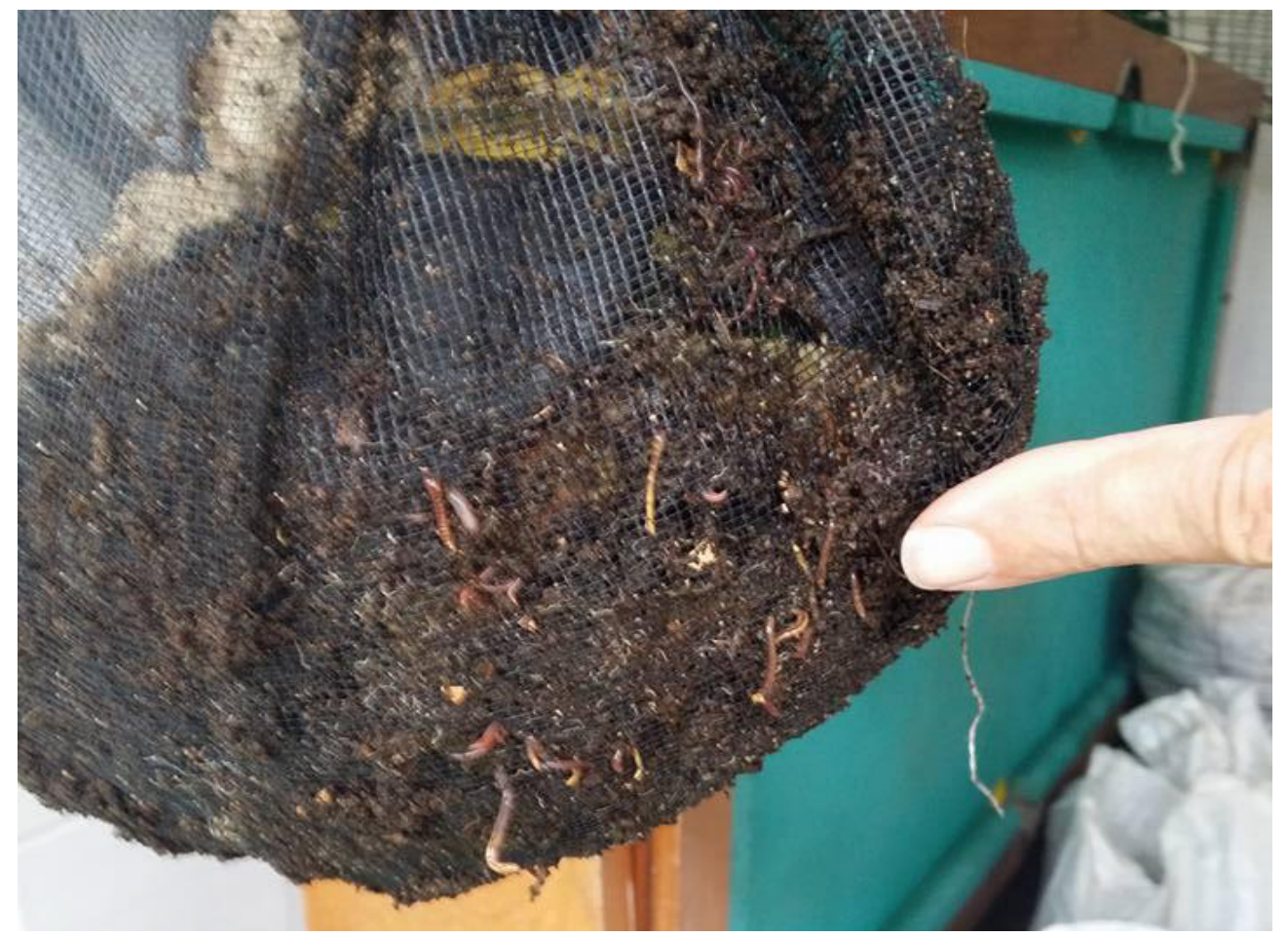

Fig.8 Separação do húmus e das minhocas - Grupo Composta SP - Facebook.

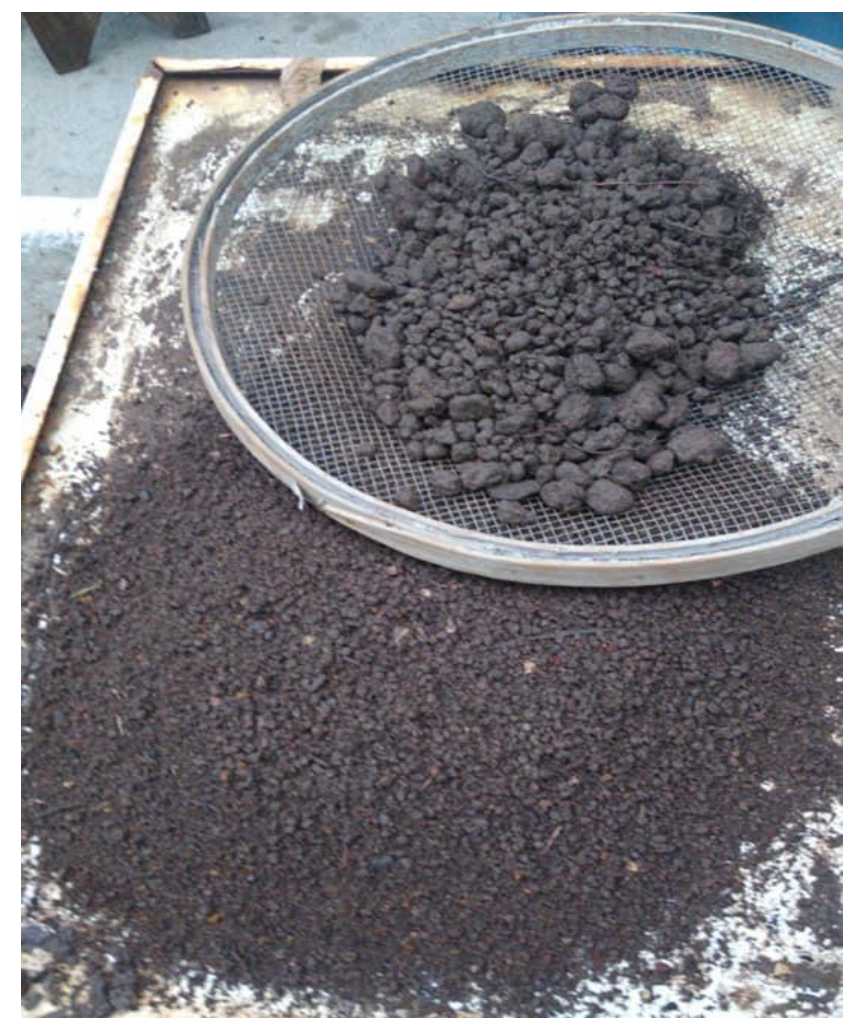

Fig. 9 Separação do húmus e das minhocas por meio da peneiração - Grupo Composta SP - Facebook. 


\section{A descentralização gera empoderamento popular}

Um fator importante em destacar é como os gestores desse projeto promoveram a parceria de diferentes segmentos da sociedade civil e descentralizaram sua gestão. Para que a execução do Composta SP ocorresse simultaneamente em diferentes localidades e para não haver apenas um centro de referência, mas diversos centros de apoio, os gestores entraram em contato com síndicos e diretorias regionais de ensino dos bairros Butantã e Penha. Ao todo, envolveram-se o total de 32 escolas públicas, além de 13 instituições privadas de ensino (escolas, organizações e cursinhos comprometidos com essa ação). Buscaram estabelecer também o envolvimento com as lideranças comunitárias que atuavam em unidades básicas de saúde, associações de bairro e igrejas.

A partir da criação dessa rede de parceria entre essas escolas, organizações e cursos, essas desenvolveram uma ação descentralizada do poder público e, por conseguinte, das partes promotoras. Os cidadãos foram envolvidos diretamente afim de promover a iniciativa. A interlocução dos executores da ação com a população que aceitou aderir ao Composta SP ocorreu por meio das mídias sociais, como anúncios de marketing via Facebook, durante o período de divulgação ao longo do início de 2014.

Pretendemos demonstrar, no conjunto de dados apresentados a seguir, algumas características importantes sobre os participantes do projeto Composta SP e mostrar informações sobre essas ações nos diferentes contextos sociais. O total de inscritos no projeto somou 8.607 e os bairros foram agrupados por subprefeituras. O maior índice de pessoas inscritas estava nos bairros situados na subprefeitura do Butantã em um total de 998 inscritos (11,5\% do total), seguidos dos inscritos na subprefeitura de Pinheiros com 974 inscritos $(11,3 \%)$ e na subprefeitura da Lapa com 882 inscritos (10,2\%). Nas últimas classificações, estavam a subprefeitura Cidade Tiradentes com 45 inscritos $(0,5 \%)$ e a subprefeitura de Perus com 38 inscritos $(0,4 \%)$. Os dados por regiões, são os seguintes: região leste apresentou $21,09 \%$ e a região oeste, $24,43 \%$ de pessoas contempladas. Do total de inscritos, $56,28 \%$ não tinham coleta seletiva em seus domicílios contrastando com 34,10\% que tinham esse serviço (Composta SP, 2014).

Observamos que houve um número reduzido de inscritos nas regiões com maior vulnerabilidade de acesso à saúde, educação, moradia, lazer e transporte, as subprefeituras de Tiradentes e Perus, em contraste com as subprefeituras de Butantã, Pinheiros e Lapa, zonas de classe média. Essa informação nos mostra que é necessária uma trans- 
formação de projetos como o Composta SP para que sejam levados em conta fatores determinantes para a saúde de populações socioeconomicamente vulneráveis. São necessárias políticas públicas que venham a suprir as necessidades da parcela da sociedade que segue restrita em seu acesso integral à informação, limitada em acessar ações públicas que tendem a uma conscientização para cidadania global e que se reflita no meio ambiente onde vivem essas comunidades.

No proximo caso apresentado, iremos observar como são fundamentais informações e ações que levem em conta os indicadores em saúde e saneamento, e prestar atenção à disparidade e iniquidades que atendam os direitos fundamentais das populações que vivem em comunidades socioeconomicamente consideradas periféricas e vulneráveis.

\section{REVOLUÇÃO DOS BALDINHOS - 2008}

Em Florianópolis, diferentemente do cenário paulistano, encontramos a iniciativa chamada "Revolução dos Baldinhos". A experiência tem sua origem em um condicionante sanitário, sobre o qual explicaremos a seguir, no bairro Chico Mendes no ano de 2008. Para lidar com tal questão, a gestão comunitária de resíduos orgânicos através da compostagem termofílica (Brasil, 2017) acabou por incrementar a saúde da população e mesmo passou a promover a agricultura urbana. O resultado dessa iniciativa é uma educação prática ambiental, como a que observamos no Composta SP, porém pautada em valores de autogestão. O resultado é um empoderamento comunitário e geração de atividades econômicas em torno de resíduos orgânicos que antes não tinham uma valorização, nem por parte dos órgãos públicos nem por parte da população local.

Essa história iniciou a partir de uma epidemia de ratos, que chamou atenção dos profissionais de saúde do Centro de Saúde do bairro Monte Cristo. Eles convocaram uma reunião com os moradores da região a fim de construir uma estratégia horizontal, com participação das pessoas do bairro, para acabar com a epidemia de ratos, fator insalubre para toda população da comunidade. A proliferação desses roedores estava relacionada com o excesso de resíduos expostos nas vias públicas do bairro e um surto de 
leptospirose. Segundo o SINAN $^{8}$, em 2008, registrou-se um total de 23 casos em leptospirose na zona metropolitana de Florianópolis, ou seja, um número de casos significativo, por ser uma enfermidade que pode levar a óbito. O número de casos reduziu gradativamente nos anos subsequentes. Muitas dessas doenças que são negligenciadas pelos gestores públicos, devido sua espacialidade e temporalidade, contribuem para a manutenção das desigualdades sociais enfrentadas no Brasil (Pereira, 2013: 33).

Duas mulheres moradoras que atuavam com a limpeza das ruas, conjuntamente com as agentes comunitárias do posto de saúde, realizaram o trabalho de sensibilização da comunidade, para que começassem a realizar uma separação adequada dos resíduos orgânicos produzidos em seus lares. Após esse momento de conscientização, a partir de conversas presenciais, as famílias que aceitaram participar da iniciativa receberam um pequeno balde para o armazenamento temporário de matéria orgânica gerada em sua casa. Cada balde, quando cheio, deveria ser levado para um posto de coleta. Havia um total de 40 Ponto de Entrega Voluntária (PEV), que foram dispostos nas ruas do bairro Monte Cristo, sendo coletados e encaminhados ao pátio de compostagem.

Esta ação, por seu caráter descentralizado, obteve da população uma recepção positiva, como é informado por integrantes do projeto em vídeos institucionais além de entrevistas publicadas ou veiculadas por meios de comunicação. O projeto logo alcançou relevância socioambiental, pois promoveu a reciclagem e o aproveitamento do material orgânico, gerando renda, reduzindo custos de coleta e criando uma nova perspectiva socioambiental. Em 2013, a iniciativa foi reconhecida e. certificada como Tecnologia Social pela Fundação Banco do Brasil, pois poderia ser replicada em diferentes contextos sociais e corroborou para uma expansão da Revolução dos Baldinhos em nível nacional.

A equipe criadora da iniciativa passou a assessorar projetos similares em outros estados brasileiros, a exemplo disso o projeto de gestão comunitária dos resíduos orgânicos da Cooperativa de Compostagem de Paragominas, no estado do Pará. Outro exemplo de resultado foi a produção de um manual e vídeo institucional em parceria com o Centro de Estudos e Promoção da Agricultura de Grupo (CEPAGRO) para assessorar o Programa Minha Casa, Minha Vida em Macaíba, no estado do rio Grande do

\footnotetext{
${ }^{8}$ Sistema de Informação de Agravos de Notificação - uma rede de informações do SUS que pela fornece dados para a investigação de casos de doenças e agravos auxilia no planejamento em saúde, para um melhor delineamento das prioridades de intervenção, além de permitir que seja avaliado o impacto das intervenções em saúde.
} 
Norte. O Serviço Social do Comércio (SESC) também foi incentivado pela iniciativa e passou a implantar pátios de compostagem institucional em três de suas unidades do estado de Santa Catarina, através de assessoramento do CEPAGRO, reciclando uma média de 30 toneladas de resíduos sólidos orgânicos ao mês.

\section{CONSIDERAÇÕES FINAIS}

O cenário atual, onde a degradação ambiental e a escassez de recursos naturais, agravada pela pandemia que vivenciamos nesse ano de 2020, nos deixa vislumbrar através dos projetos estudados, iniciados em 2014 e 2008 respectivamente, dois modelos existentes de tentativas de colaborar para uma "economia circular" que acabam por gerar também "sociedades circulares" - ou seja, uma que poderia proporcionar mais espaço para a inovação comunitária e social" (de acordo com os pesquisadores que propõe esse conceito (Research Group Obsolescence, 2019). Tanto o Composta SP como a Revolução dos Baldinhos são ações de manejo de resíduos orgânicos, cuja prática ensina às pessoas que nelas se envolvem uma experiência de participação e observação sobre os ciclos naturais dos alimentos e como esse ciclo pode ser fechado com a geração de novos alimentos. A partir da prática, aprende-se que os resíduos orgânicos quando são devidamente compostados criam húmus para que possam fertilizar novamente o solo a fim de gerar novos alimentos e reiniciar assim o ciclo da vida tanto de alimentos como de comunidades. Ambos projetos promoveram a conscientização ambiental de alguns moradores de ambas as cidades.

Estes são modelos em aperfeiçoamento. A iniciativa Composta SP teve um número pequeno de participantes, seria necessária a ampliação do número de participantes para realmente impactar numa efetiva melhora com relação à destinação final dos resíduos sólidos urbanos de origem orgânica. A Revolução dos Baldinhos teve um efeito multiplicador, hoje muitas outras cidades brasileiras reproduzem a experiência inovadora, tais como Foz do Iguaçu (PR) e Manaus (AM), onde as criadoras da Revolução dos Baldinhos foram ministrar oficinas e ensinar como realizar a compostagem termofílico que desenvolvem atualmente na comunidade Chico Mendes, em Florianópolis.

Quanto à geração de renda, observamos uma consequência em nível socioeconômico benéfica aos participantes de ambos os projetos e que proporciona, especialmente aos da Revolução dos Baldinhos, uma demanda por produtos oriundos de uma 
boa prática de manejo de seus resíduos orgânicos, com a inclusão do projeto de horta urbana.

Nesse sentido, ambas as ações, sejam por meio de parcerias do público com privado ou mesmo por meio de iniciativas da própria comunidade, confluem para novas perspectivas e benefícios a médio e longo prazo aos envolvidos nestas ações ambientais que possuem o embrião de criar o que alguns acadêmicos especialistas em manejo de florestas e de biomassa propõe como sendo uma "bioeconomia circular" (Hetemäki et ali, 2017).

Uma "bioeconomia circular" seria um paradigma possível como resultado de uma sinergia entre a "economia circular"e a "bioeconomia" (Hetemäki, 2017: 3), com foco no combate à pobreza, no estímulo de criação e uso de materiais que sejam de origem não fóssil para gerar produtos de forma eficiente e sustentável. Compreendemos que ambas iniciativas de compostagem orgânica atendem a princípios de "bioeconomia circular" e podem ser multiplicados em ações locais para que sigam gerando a circularidade de produtos e resíduos orgânicos e também possam contribuir para um retorno socioeconômico de base comunitária. Tais ações consequentemente indicam novas formas de circular economicamente os resultados por estes obtidos (húmus e biofertilizantes).

No caso da Revolução dos Baldinhos o projeto vai ainda mais adiante, pois as líderes comunitárias criaram um projeto de hortas urbanas, onde utilizam o húmus e os biofertilizantes para cultivar diversos alimentos. Antes da pandemia, organizavam também um projeto de comida comunitária, um sub-projeto intítulado Cozinha Mãe, onde também ofereciam uma festa comunitária mensal com pizza e hip hop tocado pelos jovens da comunidade. Durante a pandemia, a Cozinha Mãe adaptou-se e passou a fazer pães e biscoitos para entrega, o que mostra também como a iniciativa de tecnologia social da comunidade Chico Mendes adaptou-se às novas circunstâncias com rapidez, como exemplo de uma "economia circular" e de uma "sociedade circular".

Nesse sentido, pensamos que ambas iniciativas são exemplos de "bioeconomia circular", pois se ampliadas em escala, podem fechar um ciclo de vida dos resíduos orgânicos nos centros urbanos, criando laços desses com seus entornos rurais. No caso da revolução dos Baldinhos, é também uma iniciativa modelo de "tecnologia social" (Dagnino, Brandão \& Novaes, 2004; Pozzebon, 2015) que possui um embrião de "sociedade circular" (Research Group Obsolecence, 2019), pois a tecnologia social é empregada 
na melhoria da vida da comunidade e é também uma experiência que pode ser facilmente replicada para criar uma "economia circular", promovida por uma "sociedade circular”, a fim e gerar uma "bioeconomia circular".

\section{REFERÊNCIAS}

ABREU, Marcos Jose de. GESTÃO COMUNITÁRIA DE RESÍDUOS ORGÂNICOS: o caso do projeto revolução dos baldinhos (prb), capital social e agricultura urbana. 2013. 184 f. Dissertação (Mestrado) - Curso de Desenvolvimento Rural e Sociedade, Programa de Pós Graduação em Agroecossistemas, Universidade Federal de Santa Catarina, Florianópolis, 2013. Disponível em:

http://portal.pmf.sc.gov.br/arquivos/arquivos/pdf/10 $09 \quad 2013 \quad 12.27 .07 .3 \mathrm{a} 27 \mathrm{abe} 0 \mathrm{a} 3 \mathrm{ff} 70$ 7194fbbc41f2952efdd.pdf Acesso em: 17 maio 2020.

ASSOCIAÇÃO BRASILEIRA DE EMPRESAS DE LIMPEZA PÚBLICA - ABRELPE. Panorama dos resíduos sólidos no Brasil, 2017.

BRASIL, MINISTÉRIO DO MEIO AMBIENTE (org.) Compostagem doméstica, comunitária e institucional de resíduos orgânicos: manual de orientação. Brasília: Ministério do Meio Ambiente, 2017. 66 p.

BESEN, G. R. Coleta seletiva com inclusão de catadores: construção participativa de indicadores e índices de sustentabilidade. São Paulo, 2011. 275p. Tese (Doutorado) Faculdade de Saúde Pública, Universidade de São Paulo.

DAGNINO, R., BRANDÃO, F \& NOVAES, H. T. Sobre o marco analítico-conceitual da Tecnologia Social. In: A. Lassance Jr. et alli. Tecnologia Social: uma estratégia para o desenvolvimento. Rio de Janeiro: Fundação Banco do Brasil. Pp 15-64. 2004.

FARIAS, Eduardo. REVOLUÇÃO DOS BALDINHOS: um modelo de gestão comunitária de resíduos orgânicos que promove a agricultura urbana. 2010. 70 f. TCC (Graduação) - Curso de Agronomia, Universidade Federal de Santa Catarina, Florianópolis, 2010.

JACOBI, Pedro Roberto; BESEN, Gina Rizpah. Gestão de resíduos sólidos em São Paulo: desafios da sustentabilidade. Estud. av., São Paulo, v. 25, n. 71, p. 135-158, Apr. 2011. Available from http://www.scielo.br/scielo.php?script=sci arttext\&pid=S010340142011000100010\&ln $\mathrm{g}=\mathrm{en} \& \mathrm{nrm}=$ iso Acesso on 04 Oct. 2018. http://dx.doi.org/10.1590/S0103-40142011000100010 
McDONOUGH, William \& BRAUNGART, Michael. Cradle to Cradle: Remaking the Way We Make Things. New York: North Point Press, 2002

PEREIRA, Carlos Alexandre Rodrigues. Custo social da leptospirose no Brasil e o efeito de chuvas extremas em Nova Friburgo para o incremento de casos da doença. 2013. 109 f. Dissertação (Mestrado) - Curso de Saúde Pública e Meio Ambiente, Escola Nacional de Saúde Pública Sergio Arouca - Ensp, Fiocruz, Rio de Janeiro, 2013. Disponível em:

https://www.arca.fiocruz.br/bitstream/icict/36391/2/ve_Carlos_Alexandre_ENSP_2014 Acesso em: 17 maio 2020

PAULO, Composta São. Resultados e Relatórios: Composta SP. 2014. Disponível em: https://www.compostasaopaulo.eco.br/resultados2014/download Acesso em: 30 jun. 2019.

POZZEBON, M. “Tecnologia Social: A South American View of the Regulatory Relationship between Technology and Society". In: de Vaujany FX., Mitev N., Lanzara G.F., Mukherjee A. (eds) Materiality, Rules and Regulation. Technology, Work and Globalization. Palgrave Macmillan, London. 2015 https://doi.org/10.1057/97811375

RESEARCH GROUP OBSOLESCENCE. From Take-Make-Dispose to a Circular Society: Introduction of a new vision in six propositions. Technische University Berlin.

2019. Disponível em: https://challengeobsolescence.info/wpcontent/uploads/2019/06/190628 CS-Broschüre final_SCREEN-1.pdf

SIQUEIRA, Thais Menina Oliveira de; ABREU, Marcos José de. Fechando o ciclo dos resíduos orgânicos: compostagem inserida na vida urbana. Cienc. Cult., São Paulo, v. 68 , n. 4, p. 38-43, Dec. 2016.

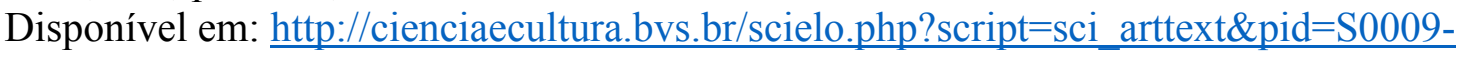

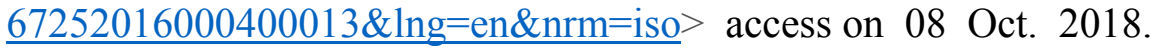
http://dx.doi.org/10.21800/2317-66602016000400013

\section{AGRADECIMENTOS}

À Universidade Federal da Integração Latino Americana - UNILA, pela concessão de bolsa de Iniciação Científica para Tobias Gustavo.

À CAPES, pela concessão de bolsa de Pós Doutorado para Barbara M. Arisi.

O presente trabalho foi realizado com apoio da Coordenação de Aperfeiçoamento de Pessoal de Nível Superior - Brasil (CAPES) - Código de Financiamento 001, e com apoio da PRPPG/UNILA.

Recebido: $31 / 08 / 2020$

Aprovado: $08 / 12 / 2020$ 